\section{Use of the ultrasound-based total malignancy score in the management of thyroid nodules}

\author{
Juan Sebastian Gomez, Luis Fernando Serrano \\ Department of Radiology, Santafe Foundation University Hospital, Bogota, Colombia
}

We read with great interest the article by Dr. Pompili et al. [1], "Use of the ultrasound-based total malignancy score in the management of thyroid nodules." First, we would like to congratulate and thank the authors for providing a novel resource in the form of the ultrasound-based total malignancy score for the management of thyroid nodules, because this is a brand-new scoring system that can guide radiologists in the diagnostic and clinical setting of managing thyroid nodules that are suspicious for malignancy. From our perspective, we concur that it is always important to review ultrasound descriptors and features for benign and malignant thyroid lesions in order to understand the likelihood of a certain thyroid nodule developing into cancer. Additionally, observing how the mechanisms for diagnosing this entity have changed over time and have ultimately evolved into the current cutting-edge method using imaging has proven to be endlessly fascinating.

We would like to highlight several vital factors regarding the methods, results, and discussion of the aforementioned study based on our literature review of PubMed, MEDLINE, and the Cochrane Library. The sample size (231 thyroid nodules) of the aforementioned study is smaller than that of other publications, such as a study regarding the Thyroid Imaging Reporting and Data System that evaluated 1,959 thyroid nodules [2] or the study written by Rosario et al. [3] that studied the diagnostic value of Doppler ultrasound in 1,502 thyroid nodules. Having a small size may lessen the internal or external validity of the study [4], as well as decreasing its statistical power. As physicians and researchers, we believe that it is crucial to have a sufficient number of patients because sample size is an extremely important parameter for interpreting the findings of a study.

Another important factor to discuss is the small number of ultrasound features that comprise the new score. In the publication, the reader is unable to find information on the background parenchyma; the presence of abnormal lymph nodes; calcification subtypes such as rim, speckled, and coarse; or margin-related characteristics, such as smooth, irregular, and poorly defined margins or the presence of extrathyroid extension $[2,5]$.

The ultrasound-based total malignancy score includes Doppler features such as the vascularity pattern in order to classify a thyroid nodule as negative or non-negative. However, this method is debatable because several publications have concluded that Doppler ultrasound is not a useful modality for distinguishing malignant from benign thyroid nodules [3].

Therefore, based on our literature review, we conclude that the small sample size of the study may have affected its validity and power, that the pattern of vascularity does not provide additional value for differentiating between benign and malignant thyroid nodules, and that additional ultrasound features of thyroid nodules, such as microcalcification subtypes or margin-related characteristics,

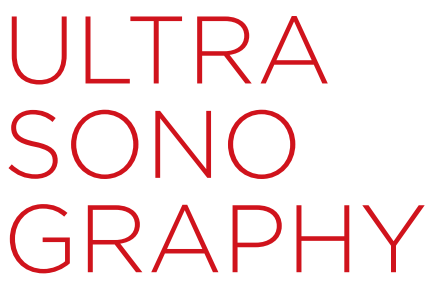

\section{LETTER}

https://doi.org/10.14366/usg. 18068 pISSN: 2288-5919 e elSSN: 2288-5943 Ultrasonography 2019;38:188-189

Received: November 20, 2018 Accepted: January 3, 2019

Correspondence to: Juan Sebastian Gomez, MD Department of Radiology, Santafe Foundation University Hospital, Carrera 7 No 117-15, Bogotá 11001000 , Colombia

Tel. +57-16030303

Fax. +57-16575714

E-mail: juan.sebastian.77gomez@ gmail.com

This is an Open Access article distributed under the terms of the Creative Commons Attribution NonCommercial License (http://creativecommons.org/ licenses/by-nc/4.0/) which permits unrestricted noncommercial use, distribution, and reproduction in any medium, provided the original work is properly cited.

Copyright @ 2019 Korean Society of Ultrasound in Medicine (KSUM)

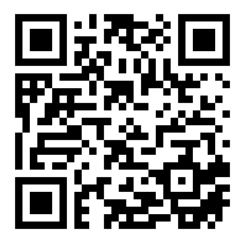

How to cite this article:

Gomez JS, Serrano LF. Use of the ultrasound based total malignancy score in the management of thyroid nodules. Ultrasonography. 2019 Apr;38(2):188-189. 
may provide vital information for the final classification of thyroid nodules.

ORCID: Juan Sebastian Gomez: https://orcid.org/0000-0001-6611-1457; Luis Fernando Serrano: https://orcid.org/0000-0002-9579-4936

\section{Conflict of Interest}

No potential conflict of interest relevant to this article was reported.

\section{References}

1. Pompili GG, Tresoldi S, Ravelli A, Primolevo A, Leo GD, Carrafiello $G$. Use of the ultrasound-based total malignancy score in the management of thyroid nodules. Ultrasonography 2018;37:315322.
2. Horvath E, Majlis S, Rossi R, Franco C, Niedmann JP, Castro A, et al. An ultrasonogram reporting system for thyroid nodules stratifying cancer risk for clinical management. J Clin Endocrinol Metab 2009:94:1748-1751.

3. Rosario PW, Silva AL, Borges MA, Calsolari MR. Is Doppler ultrasound of additional value to gray-scale ultrasound in differentiating malignant and benign thyroid nodules? Arch Endocrinol Metab 2015;59:79-83.

4. Hajian-Tilaki K. Sample size estimation in diagnostic test studies of biomedical informatics. J Biomed Inform 2014;48:193-204.

5. Richman DM, Benson CB, Doubilet PM, Peters HE, Huang SA, Asch $E$, et al. Thyroid nodules in pediatric patients: sonographic characteristics and Ikelihood of cancer. Radiology 2018;288:591599.

\section{Response}

\section{Giovanni Guido Pompili}

\section{Radiology Unit 1, ASST Santi Paolo e Carlo, Milan, Italy}

I thank you for the brevity and clarity of your statements. I do believe that risk of malignancy can still be assessed with power Doppler, as stated by Rosario et al. [1], when predominantly or exclusively central flow was considered although this flow was seen in only $15 \%$ of malignant nodules. The recent Thyroid Imaging Reporting and Data System (TI-RADS) guidelines do not consider Doppler color flow as a malignant predictor but I know a lot of prospective works are currently performing about that considering that a lack of intranodular vascularity can predict malignancy [2]. I believe that your considerations about calcifications are correct, as already cited in the TI-RADS classification score $[3,4]$. I think that the Pompili et al. [5] original article highlights another interesting aspect forgot in the recent TI-RADS score which is the singleness of a nodule.

\section{References}

1. Rosario PW, da Silva AL, Nunes MB, Borges MA. Risk of malignancy in thyroid nodules using the American College of Radiology Thyroid Imaging Reporting and Data System in the NIFTP era. Horm Metab Res 2018;50:735-737.

2. Yang GC, Fried KO. Most thyroid cancers detected by sonography lack intranodular vascularity on color Doppler imaging: review of the literature and sonographic-pathologic correlations for 698 thyroid neoplasms. J Ultrasound Med 2017;36:89-94.

3. Tessler FN, Middleton WD, Grant EG. Thyroid Imaging Reporting and Data System (TI-RADS): a user's guide. Radiology 2018;287:1082.

4. Middleton WD, Teefey SA, Reading CC, Langer JE, Beland MD, Szabunio MM, et al. Comparison of performance characteristics of American College of Radiology TI-RADS, Korean Society of Thyroid Radiology TIRADS, and American Thyroid Association guidelines. AJR Am J Roentgenol 2018;210:1148-1154.

5. Pompili GG, Tresoldi S, Ravelli A, Primolevo A, Leo GD, Carrafiello G. Use of the ultrasound-based total malignancy score in the management of thyroid nodules. Ultrasonography 2018;37:315322. 